\title{
Invasive chestnut gall wasp Dryocosmus kuriphilus (Hymenoptera: Cynipidae), its native parasitoid community and association with oak gall wasps in Slovenia
}

\author{
KATARINA KOS ${ }^{1}$, Eva KRISTON ${ }^{2}$ and GeORge MELIKA ${ }^{2}$ \\ ${ }^{1}$ Department of Agronomy, Biotechnical Faculty, University of Ljubljana, Ljubljana, Slovenia; e-mail: katarina.kos@bf.uni-lj.si \\ ${ }^{2}$ Plant Health and Molecular Biology Laboratory, National Food Chain Safety Office, Budapest, Hungary; \\ e-mails: kristone@nebih.gov.hu; melikageorge@gmail.com
}

\begin{abstract}
Key words. Hymenoptera, Cynipidae, Dryocosmus kuriphilus, ACGW - Asian chestnut galls wasp, oak cynipids, parasitoid recruitment, native fauna, Slovenia
\end{abstract}

\begin{abstract}
The Asian chestnut gall wasp (ACGW), Dryocosmus kuriphilus Yasumatsu (Hymenoptera: Cynipidae), is a global pest of chestnut trees. This pest was first recorded in Slovenia in 2005. Despite strict phytosanitary measures it was present throughout the country in native chestnut stands by 2013. We provide here the first overview of the parasitoids of ACGW in Slovenia recorded over a 4-year period and the direct interactions between parasitoid communities attacking hosts on chestnut and oaks at the same sites. A total of 27 species of native parasitoids that normally parasitize oak cynipids emerged from ACGW galls. The most abundant species were Torymus flavipes and Eupelmus urozonus. Seven species appear to be geographically well distributed in Slovenia. Twelve species of oak gall wasp were parasitized by 19 species of parasitoids. All native parasitoids have broad host ranges, so a large parasitoid diversity within this community can be expected. This is a novel study comparing the parasitoid communities associated with chestnut and oak galls.
\end{abstract}

\section{INTRODUCTION}

The Asian chestnut gall wasp, Dryocosmus kuriphilus Yasumatsu (Hymenoptera: Cynipidae) was first recorded in Slovenia in 2005 on chestnut plants that came from an Italian nursery in Cuneo and since then it has spread nearly throughout the whole of Slovenia by infesting native stands of European sweet chestnut (Castanea sativa Mill.) (Knapič et al., 2010). This invasive pest, which is native to China, is considered to be the most serious pest of chestnut trees, Castanea spp. (Fagaceae) and their hybrids, causing severe fruit yield loss due to the galls they induce on leaves and shoots (Murakami et al., 1980; Graziosi \& Santi, 2008; Quacchia et al., 2008). In Italy, during the period 2004-2006 fruit yield was reduced by $65-85 \%$ due to the ACGW (Bosio et al., 2013). ACGW was accidentally introduced into several countries and moved from Asia to USA and Europe. The first record of ACGW in Italy was in 2002 and, in the following years, it became widely distributed and established in Italy, France, Switzerland, Slovenia, Croatia and Hungary. Its presence has also been confirmed in The Netherlands (2010), Austria (2011), Czech Republic (2012), Slovakia (2012), Spain (2012) and Germany (2012) (Quacchia et al., 2014). Strict phytosanitary measures and an eradication program coordinated by the Phytosanitary Administration of the Republic Slovenia resulted in absence of this pest in most of Slovenia by 2009. This was achieved by immediately destroying all plants showing visible symptoms, weekly checking for galls within the focus zone from May until the end of July, a ban on selling chestnut plants from the demarcated area for planting until June the following year and an obligation to notify and report further findings of galls (Knapič et al., 2010). However, despite these strict measures, from 2009 until 2013 ACGW occupied most Slovenian forests containing sweet chestnut and chestnut orchards (ARSFSVSPP, 2014), mostly because it is thelytokous and is easily spread on infested twigs and naturally, with the adults transferred by humans to more distant places. A single female can therefore rapidly establish a population at a new location (Abe et al., 2007).

Based on the statistical data for 2009, Slovenia is one of the most forested countries in Europe, with forests covering up to $59.9 \%$ of the land, just after Finland and Sweden (Drevo, 2011). Slovenia has natural mixed forests containing sweet chestnut (C. sativa) in the continental part, whereas in Slovenian Istria and the Goriška region chestnuts are usually mixed with native species of oak, i.e., Quercus petraea (Mattuschka) Liebl., Q. robur L., Q. pubescens Willd. and Q. cerris L. (Drevo, 2011).

Worldwide, there are about 1,300 gall wasps species described that induce the formation of plant galls (Csóka et al., 2005). The highly complex oak galls contain communities of insects consisting of a variety of gall inducers, inquilines and natural enemies (Hayward \& Stone, 2005; Askew et al., 2013). In the case of ACGW parasitization by native and introduced parasitoids provides the best control, since the larvae of the pest are well protected inside the galls, which makes chemical and mechanical control difficult (Aebi et al., 2007; Cooper \& Rieske, 2007).

Our ultimate goal is to gain a more complete understanding of the ecological interactions between ACGW and its parasitoids that are native to Slovenia and most likely the same as those parasitizing gall wasps on neighbouring oaks, since all the parasitoid species reared from ACGW 


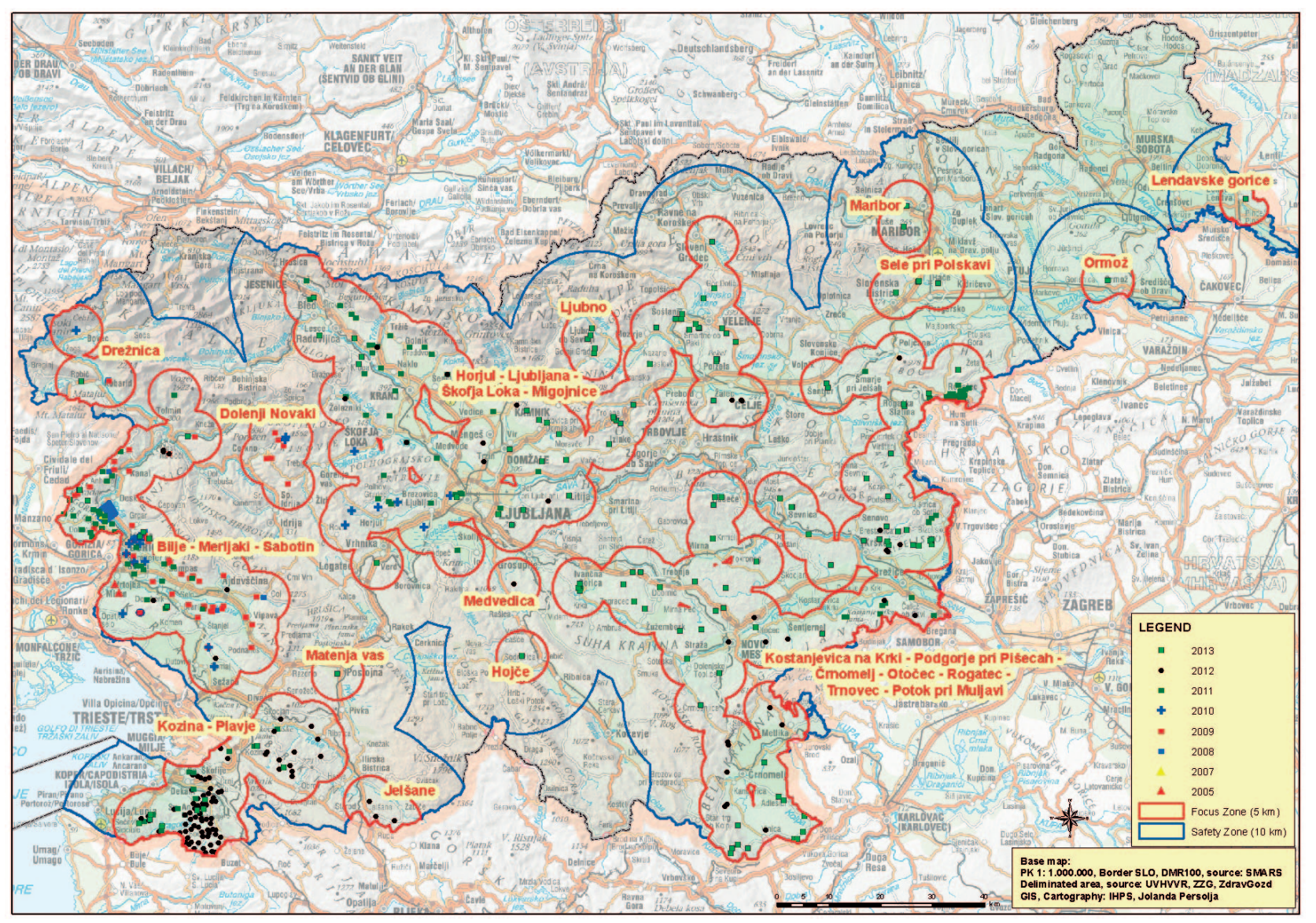

Fig. 1. Map of Slovenia showing the distribution of ACGW recorded in 2005-2013 (ARSFSVSPP).

are species known to be common parasitoids of oak cynipid gall wasps and typically those with broad host ranges (Quacchia et al., 2012; Askew et al., 2013; Matošević \& Melika, 2013). We know that oak cynipid gall communities are relatively "closed", in that a characteristic set of parasitoids attack hosts in a specific habitat (gall) (Stone et al., 2002). However, we know very little about the evolutionary history of such species-rich insect communities. Closely related hosts are commonly attacked by similar sets of parasitoids (Bailey et al., 2009), but we do not know whether this pattern can be explained by parallel patterns of diversification across trophic levels (Host tracking hypothesis; as in some highly specific parasite-host interactions, e.g. Schluter, 2000), or the fact that related hosts are often similar in traits that result in parasitoid recruitment from local assemblages (Ecological sorting hypothesis; e.g. Weiher \& Keddy, 1999).

The aim of this study was to identify the parasitoids reared from overwintering and newly formed ACGW galls in Slovenia and compare our results with those from other countries. In addition, the local parasitoid community associated with oak gall wasps is compared with the chalcid parasitoid community from ACGW, providing us with important information about parasitoid host shifts and adaptation to a new host in forest ecosystems. This kind of information is presented for the first time and is also important because the imported parasitoid Torymus sinensis Kamijo was introduced into Slovenia in 2015 by the
Slovenian Agriculture and Forestry Service Nova Gorica and we will be able to obtain an overview of the chestnut and oak gall wasp parasitoid community before and after its establishment.

\section{MATERIAL AND METHODS}

\section{Sampling of ACGW galls}

Sampling of ACGW galls took place from March to April (overwintering galls) and from late May to the first half of June (collecting newly formed galls) from 2010 to 2013, mostly in the Slovenian Littoral region (southwest) on the border with Italy. During 2012 and 2013, samples were also taken from other parts of Slovenia, i.e., Central Slovenia, Slovenian Styria in the northeast and Lower Carniola in the southeast of Slovenia, where chestnut occurs mostly in natural stands. Throughout Slovenia there are about 32 ha of chestnut orchards. From a total of 29 locations, we gathered 22,619 overwintering galls and 27,155 newly formed galls, which were collected by hand using a tree cutter. Galls were subsequently transported to the Laboratory of Phytomedicine at the Biotechnical Faculty in Ljubljana and stored in plastic rearing boxes at room temperature until the inhabitants emerged. Rearing boxes were checked daily and, after emergence, wasps from each sample were preserved in $70 \%$ ethanol and later sent for identification to the Plant Health and Molecular Biology Laboratory of the National Food Chain Safety Office in Budapest, Hungary. Locations were chosen in relation to the first appearance and very high prevalence of ACGW in the vicinity of Nova Gorica and, later, locations all around Slovenia into which ACGW was spreading. 
TABLE 1. Number of species of parasitoids belonging to 6 families and total number of adult male and female parasitoids that emerged from overwintering (ow) and newly-formed D. kuriphilus galls in 2010-2013.

\begin{tabular}{|c|c|c|c|c|c|c|}
\hline \multirow{2}{*}{ Parasitoid species } & \multirow{2}{*}{ Family } & \multicolumn{2}{|c|}{ ow galls } & \multicolumn{2}{|c|}{ new galls } & \multirow{2}{*}{ Sum } \\
\hline & & $\mathrm{M}$ & $\mathrm{F}$ & M & $\mathrm{F}$ & \\
\hline Aprostocetus biorrhizae (Szelényi) ${ }^{\mathrm{a}}$ & Eulophidae & 0 & 4 & 0 & 0 & 4 \\
\hline Aprostocetus aethiops (Zetterstedt) ${ }^{\mathrm{a}}$ & Eulophidae & 2 & 0 & 0 & 0 & 2 \\
\hline Aprostocetus glandicola Graham $^{\mathrm{a}}$ & Eulophidae & 1 & 0 & 0 & 0 & 1 \\
\hline Aulogymnus skianeuros (Ratzeburg) ${ }^{\mathrm{a}}$ & Eulophidae & 3 & 10 & 0 & 0 & 13 \\
\hline Baryscapus sp. Forster ${ }^{\mathrm{a}}$ & Eulophidae & 0 & 27 & 0 & 0 & 27 \\
\hline Cecidostiba semifascia (Walker) ${ }^{\mathrm{a}}$ & Pteromalidae & 2 & 1 & 0 & 0 & 3 \\
\hline Eupelmus annulatus $\mathrm{Nees}^{\mathrm{ab}}$ & Eupelmidae & 57 & 24 & 76 & 110 & 267 \\
\hline Eupelmus splendens Giraud $^{\mathrm{a}}$ & Eupelmidae & 1 & 6 & 0 & 0 & 7 \\
\hline Eupelmus urozonus Dalman ${ }^{\mathrm{ab}}$ & Eupelmidae & 64 & 43 & 124 & 223 & 454 \\
\hline Eupelmus (= Macroneura) vesicularis (Retzius) ${ }^{\mathrm{b}}$ & Eupelmidae & 0 & 0 & 0 & 4 & 4 \\
\hline Eurytoma brunniventris Ratzeburg ab & Eurytomidae & 1 & 0 & 9 & 51 & 61 \\
\hline Eurytoma pistacina Rondani $^{\mathrm{ab}}$ & Eurytomidae & 31 & 19 & 3 & 2 & 55 \\
\hline Megastigmus dorsalis (Fabricius) ${ }^{\mathrm{ab}}$ & Torymidae & 3 & 2 & 43 & 103 & 151 \\
\hline Mesopolobus albitarsus (Walker) ${ }^{\mathrm{a}}$ & Pteromalidae & 0 & 1 & 0 & 0 & 1 \\
\hline Mesopolobus fasciiventris Westwood $^{\mathrm{b}}$ & Pteromalidae & 0 & 0 & 13 & 19 & 32 \\
\hline Mesopolobus sericeus (Forster) ${ }^{\mathrm{b}}$ & Pteromalidae & 0 & 0 & 14 & 35 & 49 \\
\hline Mesopolobus tarsatus (Nees) ${ }^{\mathrm{b}}$ & Pteromalidae & 0 & 0 & 0 & 9 & 9 \\
\hline Mesopolobus tibialis (Westwood) ${ }^{\mathrm{b}}$ & Pteromalidae & 0 & 0 & 63 & 65 & 128 \\
\hline Ormyrus pomaceus (Geoffroy) ${ }^{\mathrm{b}}$ & Ormyridae & 0 & 0 & 213 & 33 & 246 \\
\hline Pediobius saulius (Walker) ${ }^{\mathrm{b}}$ & Eulophidae & 1 & 1 & 0 & 0 & 2 \\
\hline Sycophila biguttata (Swederus) ${ }^{\mathrm{b}}$ & Eurytomidae & 0 & 0 & 3 & 29 & 32 \\
\hline Sycophila flavicollis (Walker) ${ }^{\mathrm{b}}$ & Eurytomidae & 0 & 0 & 7 & 18 & 25 \\
\hline Sycophila variegata (Curtis) ${ }^{\mathrm{b}}$ & Eurytomidae & 0 & 0 & 0 & 6 & 6 \\
\hline Torymus auratus (Geoffroy in Fourcroy) ${ }^{\mathrm{b}}$ & Torymidae & 0 & 0 & 4 & 7 & 11 \\
\hline Torymus flavipes (Walker) ${ }^{\mathrm{ab}}$ & Torymidae & 7 & 19 & 227 & 529 & 782 \\
\hline Torymus formosus (Walker) ${ }^{\mathrm{b}}$ & Torymidae & 0 & 0 & 16 & 68 & 84 \\
\hline Torymus geranii (Walker) ${ }^{\mathrm{b}}$ & Torymidae & 0 & 0 & 18 & 48 & 66 \\
\hline Sum & & 173 & 157 & 833 & 1,359 & 2,522 \\
\hline
\end{tabular}

${ }^{\mathrm{a}}$ Species emerged only from overwintering galls; ${ }^{\mathrm{b}}$ species emerged only from newly formed galls; ${ }^{\mathrm{ab}}$ species emerged from both types of galls.

The number of adults of each species of parasitoid that emerged from galls collected at 7 locations in the Slovenian Littoral was counted and a standardized percentage emergence (er) calculated (Quacchia et al., 2012): er = (number of parasitoids/total number of galls per sample)*100 to evaluate relative parasitoid abundance per unit of sampling effort (gall). This percentage emergence is not a measure of the exact percentage parasitism, but does provide a method of determining relative parasitoid abundance per unit of sampling effort. As ACGW galls are multilocular, many parasitoids of the same species could emerge from the same gall. Numerous dissections of ACGW galls and calculation of larval chamber numbers, revealed that the average number of larval chambers per gall of ACGW is 2-3. Thus, dividing the relative parasitoid abundance per unit of sampling effort (gall) by average number of larval chambers per gall gives a more precise estimate of the parasitization level. The 7 locations were selected on the basis of the results for all 4 years (2010-2013) and it includes natural stands and chestnut orchards with a very high prevalence of ACGW. At other locations ACGW appeared later, in 2012.

\section{Sampling of oak galls}

Oak galls were sampled at 6 locations (Slovenian Littoral; southwest part of Slovenia) in May and in October 2011, where ACGW galls were also collected. Oak galls were collected by hand and with a branch cutter from Quercus petraea, Q. pubescens, $Q$. robur and $Q$. cerris in late May and early June (sexual galls) and at the beginning of October (asexual galls) in 2011.
Each sample was examined and galls from leaves, branches, catkins and buds were collected. Rearing took place at the Laboratory of Phytomedicine at the Biotechnical Faculty in Ljubljana and parasitoids were sent to the Institute of Evolutionary Biology, University of Edinburgh, Scotland, U.K., for identification preserved in vials containing $70 \%$ ethanol.

\section{Parasitoid species identification}

For the identification of Chalcidoidea parasitoids an unpublished key produced by R.R. Askew (Manchester, UK) was used, which is the basic identification tool that has been used for decades in the research on parasitoid communities of oak gall wasps. The catalogue of oak gall wasp parasitoids (Askew et al., 2013) is based exclusively on this key.

\section{RESULTS}

In the period from 2010-2013, 49,774 galls were collected and 2,522 specimens of parasitoids emerged. 27 species of native parasitoids belonging to six Chalcidoidea families were recorded (Table 1). The parasitoid species most commonly encountered in our research (Table 1) was T. flavipes (Walker), which made up $31 \%$ of all specimens recorded, followed by Eupelmus urozonus Dalman (18\%), E. annulatus Nees (10\%) and Ormyrus pomaceus (Geoffroy) $(9.7 \%)$. 
TABLE 2. Total number of parasitoids and standardized emergence [number of overwintering (ow) and newly-formed (new) galls, $\mathrm{np}=$ number of parasitoids, er/100 galls - number of parasitoids that emerged per 100 galls] at 7 locations in the Slovenian Littoral in the period from 2010-2013.

\begin{tabular}{lcccccc}
\hline Location & $\begin{array}{c}\text { ow } \\
\text { galls }\end{array}$ & $\begin{array}{c}\text { np } \\
\text { ow }\end{array}$ & $\begin{array}{c}\text { er/100 } \\
\text { galls ow }\end{array}$ & $\begin{array}{c}\text { new } \\
\text { galls }\end{array}$ & $\begin{array}{c}\text { np } \\
\text { new }\end{array}$ & $\begin{array}{c}\mathrm{er} / 100 \\
\text { galls new }\end{array}$ \\
\hline Panovec & 5,968 & 8 & 0.1 & 3,637 & 91 & 2.5 \\
Kromberk & 3,278 & 111 & 3.4 & 2,148 & 304 & 14.2 \\
Ravnica & 2,711 & 115 & 4.2 & 2,871 & 149 & 5.2 \\
Grgarske ravne & 1,585 & 48 & 3.0 & 1,190 & 462 & 38.8 \\
Orehovica & 3,393 & 15 & 0.4 & 2,403 & 286 & 11.9 \\
Renče-Merljaki & 2,385 & 26 & 1.1 & 2,826 & 29 & 1.0 \\
Stara Gora & 1,439 & 4 & 0.3 & 1,114 & 34 & 3.1 \\
Sum/Average & 20,759 & 327 & 1.6 & 16,189 & 1,355 & 8.4 \\
\hline
\end{tabular}

Of all the specimens emerged, about $60 \%$ were adult females and $40 \%$ males (Table 1). Eight species belonging to six genera and one unidentified species belonging to the genus Baryscapus emerged only from overwintering ACGW galls and most of them belong to the Eulophidae, while 12 species were reared only from newly-formed galls.

Most of the galls $(75 \%)$ were collected at 7 locations in the Slovenian Littoral (Table 2), where ACGW had been present for many years (even from 2005) and 67\% of all the parasitoids were recorded there. Only at these locations were parasitoids recorded that emerged from both types of ACGW galls.

The average standardized emergence (Table 2) was 1.6 parasitoids per 100 overwintering galls and 8.4 parasitoids from 100 newly formed galls. The numbers emerging recorded at Grgarske Ravne was rather high due to the abundance there of $T$. flavipes and $O$. pomaceus in 2011. The numbers emerging at Kromberk and Orehovica were the next highest, where $T$. flavipes was the predominant species followed by $O$. pomaceus, E. annulatus and E. urozonus.

It is interesting that native parasitoids were able to parasitize a new host after such a short time; in Slovenian Styria and Lower Carniola, ACGW was recorded in 2012 and 2013, and in 2013 we recorded several parasitized galls. Of 2,688 galls collected at 3 locations in Styria, 236 specimens of 9 native parasitoids belonging to 5 families emerged and 123 specimens belonging to 6 species and 4 families emerged from 2,429 galls collected in Lower Carniola. Four species, E. urozonus, Sycophila flavicollis (Walker), Torymus flavipes and Torymus geranii (Walker) were recorded in all 4 Slovenian regions and Eupelmus annulatus, Megastigmus dorsalis (Fabricius), Mesopolobus fasciiventris Westwood, Mesopolobus sericeus (Forster) and Ormyrus pomaceus also seem to be well geographically distributed (Table 3). In addition, most of these species were recorded parasitizing both sexual and asexual gall generations of cynipids associated with oak (Table 4).

At 6 locations in the Slovenian Littoral, galls of 31 species of oak gall wasps were recorded and additional specimens collected in buds and on catkins. Twelve species of oak gall wasps were parasitized by 19 species of parasitoids and a few other specimens were classified to 5 genera
(Table 4). In relation to the shift of parasitoids from oak to chestnut gall wasp, species that emerged from ACGW galls can be added and it can now be stated that at least 33 species of parasitoids attack oak gall wasps in Slovenia. Biorrhiza pallida Olivier was attacked by 11 native species of parasitoid, which were also mostly recorded in ACGW galls at the same locations (Table 4). This suggests that most parasitoids that locally parasitize oak gall wasps are able to shift to other hosts, such as ACGW as well as those on herbaceous host plants.

\section{DISCUSSION}

Although ACGW arrived in Europe without its natural enemies it was quickly parasitized throughout Slovenia by native parasitoids that normally attack oak and rose galls induced by related cynipid gall wasps.

The establishment and efficacy of the native parasitoids from cynipid galls on oaks and herbaceous plants in parasitizing ACGW is now under investigation in many European countries in which this pest has recently become established (Aebi et al., 2006, 2007; Cooper \& Rieske, 2007; Quacchia et al., 2012; Matošević \& Melika, 2013; Melika et al., 2013; Szabó et al., 2014; Francati et al., 2015). However, the efficacy of native parasitoids is very low and very far from the acceptable economic threshold, in spite of their rapid acceptance of ACGW as a new host. The estimated efficacy of parasitoids in Italy-Croatia-Hungary is between 2.0-4.7\%. (Aebi et al., 2007, Gibbs et al., 2011; Quacchia et al., 2012; Szabó et al., 2014), in rare cases (at some localities in Italy) 32\% efficacy is recorded associated with a very high abundance of Torymus flavipes (Santi \& Maini, 2011).

This is the first research on the parasitization of ACGW by native parasitoids, in particular those belonging to the oak gall parasitoid community in Slovenia. A total of 27 species of parasitoid belonging to six Chalcidoidea families (Eupelmidae - 4 species, Eulophidae - 6 species, Eurytomidae -4 species, Ormyridae -1 species, Pteromalidae -7 species and Torymidae -5 species) were recorded parasitizing ACGW galls all over Slovenia, which emerged from overwintering or newly-formed galls or both. Quacchia et al. (2012) also records twenty-seven native species of chalcid parasitoids attacking ACGW in Italy, belonging to six families (Eurytomidae, Pteromalidae, Torymidae, Eupelmidae, Ormyridae and Eulophidae) and species of the genera Aprostocetus, Aulogymnus, Baryscapus, Pediobius and Cecidostiba (Table 3). Among the species identified in Italy, sixteen species were also recorded in Slovenia. We recorded 13 parasitoid species in common with neighbouring Croatia (Matošević \& Melika, 2013) and just two, i.e., Mesopolobus amaenus Walker and M. dubius Girauld \& Dodd, are recorded in Croatia but not in Slovenia.

The results of a comparison of the emergence of parasitoids from overwintering and newly-formed galls indicate that considerably more parasitoids were obtained from newly-formed galls. This also implies that the majority of the parasitoids are not synchronized with their new host and native parasitoids are thus not as efficient in controlling ACGW populations as T. sinensis, which emerges 
TABLE 3. Species of parasitoids that emerged from D. kuriphilus galls in 2010-2013 collected at locations in 4 Slovenian regions. Species in bold are also recorded in Italy parasitizing D. kuriphilus galls (Quacchia et al., 2012; Francati et al., 2015).

\begin{tabular}{|c|c|c|c|c|c|c|c|c|c|}
\hline \multirow{2}{*}{$\begin{array}{l}\text { Year } \\
\text { Slovenian region }\end{array}$} & \multirow{2}{*}{$\frac{2010}{\mathrm{SL}}$} & \multicolumn{2}{|l|}{2011} & \multicolumn{2}{|l|}{2012} & \multicolumn{4}{|c|}{2013} \\
\hline & & SL & $\mathrm{CS}$ & SL & $\mathrm{CS}$ & SL & $\mathrm{CS}$ & SS & $\mathrm{LC}$ \\
\hline \multicolumn{10}{|l|}{ Parasitoid species } \\
\hline Aprostocetus biorrhizae & & & & $\mathrm{GR}, \mathrm{K}, \mathrm{RA}$ & & & & & \\
\hline Aprostocetus aethiops & & $\mathrm{O}$ & & & & & & & \\
\hline Aprostocetus glandicola & & & & $\mathrm{RM}$ & & & & & \\
\hline Aulogymnus skianeuros & & $\mathrm{O}, \mathrm{RA}$ & & GR & & & & & \\
\hline Baryscapus sp. & & & & $\mathrm{K}, \mathrm{RA}$ & & & & & \\
\hline Cecidostiba semifascia & & $\mathrm{O}$ & & & & & & & \\
\hline Eupelmus annulatus & & $\mathrm{K}, \mathrm{LI}, \mathrm{RM}$ & & $\mathrm{K}, \mathrm{RA}, \mathrm{V}$ & & $\mathrm{RA}, \mathrm{V}$ & & RO & KK \\
\hline Eupelmus splendens & $P$ & & & $\mathrm{O}, \mathrm{RA}, \mathrm{RM}$ & LB & & & & \\
\hline Eupelmus urozonus & & ČO,GR,K,O, P,PA,RA,S & $\mathrm{PC}$ & $\mathrm{GR}, \mathrm{K}, \mathrm{O}, \mathrm{P}, \mathrm{RA}, \mathrm{SG}, \mathrm{V}$ & LB & B & $\mathrm{D}, \mathrm{LR}$ & $\mathrm{LO}, \mathrm{Z}$ & $\check{C} \mathrm{~S}$ \\
\hline $\begin{array}{l}\text { Eupelmus (= Macroneura) } \\
\text { vesicularis }\end{array}$ & & $\mathrm{GR}, \mathrm{K}$ & $\mathrm{PC}$ & & & & & & \\
\hline Eurytoma brunniventris & & $\mathrm{GR}, \mathrm{K}, \mathrm{O}, \mathrm{RA}, \mathrm{RM}$ & $\mathrm{PC}$ & $\mathrm{GR}, \mathrm{K}$ & & $\mathrm{V}$ & & & \\
\hline Eurytoma pistacina & & $\mathrm{K}, \mathrm{RA}$ & & $\mathrm{GR}, \mathrm{K}, \mathrm{O}, \mathrm{RA}$ & & RA & & LO & \\
\hline Megastigmus dorsalis & $P$ & ČO,GR,K,LI,O,P,PA,RA,SG & & $\mathrm{K}, \mathrm{O}, \mathrm{P}, \mathrm{RA}, \mathrm{V}$ & & & LB & LO & \\
\hline Mesopolobus albitarsus & $P$ & & & & & & & & \\
\hline Mesopolobus fasciiventris & $\mathrm{P}$ & C̆O,O & SI & $\mathrm{K}, \mathrm{V}$ & LB & & LR & RO & \\
\hline Mesopolobus mediterraneus* & & & & & & $*$ & & & \\
\hline Mesopolobus sericeus & & O,PA,RA,RM,SG & $\mathrm{PC}$ & GR,K & & $\mathrm{V}$ & LB & & KK \\
\hline Mesopolobus tarsatus & & $\mathrm{O}$ & & & & & & & \\
\hline Mesopolobus tibialis & & GR,K,LI,O,RM & & GR,O,RA & & & & & \\
\hline Ormyrus pomaceus & & $\mathrm{GR}, \mathrm{K}, \mathrm{O}, \mathrm{PA}, \mathrm{RA}, \mathrm{RM}$ & & $\mathrm{K}, \mathrm{V}$ & & $\mathrm{V}$ & LB & LO,RO & \\
\hline Pediobius saulius & & & & $\mathrm{K}$ & & & & & \\
\hline Sycophila biguttata & & $\mathrm{GR}, \mathrm{K}, \mathrm{LI}, \mathrm{O}, \mathrm{RA}$ & SI & & & & & & \\
\hline Sycophila flavicollis & & & & & & $\mathrm{V}$ & LB & LO,RO & $\check{C} \mathrm{~S}$ \\
\hline Sycophila variegata & & $\mathrm{P}, \mathrm{RM}$ & & & & & & & \\
\hline Torymus auratus & & & & SG & & & & & \\
\hline Torymus flavipes & $\mathrm{P}$ & ČO,GR,K,LI,O,P,PA,RA,RM & PC,SI, S̆ & $\mathrm{GR}, \mathrm{K}, \mathrm{O}, \mathrm{P}, \mathrm{RA}, \mathrm{RM}, \mathrm{SG}, \mathrm{V}$ & & $\mathrm{RA}, \mathrm{B}$ & LB,LR & LO,RO & ,KK,NM \\
\hline Torymus formosus & & $\mathrm{O}, \mathrm{RA}$ & & & & & & & \\
\hline Torymus geranii & $\mathrm{P}$ & O,P,PA,RA,RM & & $\mathrm{O}, \mathrm{P}, \mathrm{V}$ & & & $\mathrm{D}, \mathrm{LB}, \mathrm{LR}$ & LO,RO & KK \\
\hline
\end{tabular}

*Collected in 2013 by M. Jurc in the sub-Mediterranean region (Jurc et al., 2013). SL - Slovenian Littoral: B - Baske, ČO - Čolnica, GR - Grgarske Ravne, K - Kromberk, LI - Lig, O - Orehovica, P - Panovec, PA - Paljevo, RA - Ravnica, RM - Renče Merljaki, SG Stara Gora, V - Vitovlje; CS - Central Slovenia: D - Dolsko, LB - Ljubljana Brdo, LR - Ljubljana Rožnik, PC - Planina pri Cerknem, SI - Slap ob Idrijci, Š - Šentjošt; SS - Slovenian Styria: LO - Log, RO - Rogatec, Ž - Žetale; LC - Lower Carniola: ČS - Čatež ob Savi, KK - Kostanjevica na Krki, NM - Novo mesto.

from overwintering galls and, like ACGW, has just one generation per year (Quacchia et al., 2012). The high number of male specimens that emerged from overwintering galls (Table 1) may be due to the abundance of the new host, in which excess male eggs would not otherwise be laid (Quacchia et al., 2012).

The parasitoid species most frequently recorded was $T$. flavipes, followed by Eupelmus urozonus, E. annulatus and Ormyrus pomaceus. T. flavipes is also commonly recorded by Matošević \& Melika in Croatia (2013) and Santi \& Maini in the Bologna district of Italy (2011) and in small numbers in Italy by Quacchia et al. (2012) and Francati et al. (2015).

The numbers emerging in our study are slightly higher than those recorded in Croatia (Matošević \& Melika, 2013) and Italy (Quacchia et al., 2012), perhaps because of the floral and faunal diversity of the forests in which most of the locations were situated. The percentage of parasitism in our study was estimated to be about $5 \%$ per sampling unit (gall), but when the multilocular nature of the galls is taken into account, the estimated percentage parasitism is $2 \%$, or even lower. This is also confirmed by the results from Italy (Aebi et al., 2007; Quacchia et al., 2012).

The most abundant parasitoids parasitizing ACGW in Slovenia were T. flavipes, Eupelmus urozonus, E. annulatus and Ormyrus pomaceus, which make up $68 \%$ of all the parasitoids that emerged. There are some positive interactions between parasitoids of chestnut and oak gall wasps. Thirteen species of parasitoids emerged from both chestnut and oak galls, but further work on oak gall parasitoids should be done, since oak galls are harder to find and collect than chestnut galls, which accounts for the lower number of oak galls collected and the fewer parasitoids that emerged from them. It does not mean that the percentage parasitism of oak galls is lower than of ACGW, just that the sampling effort of oak galls was lower than that of ACGW and thus we do not have enough data to compare the percentage parasitism of these two hosts.

It is also worth mentioning that the native species recorded in our study mainly have broad host ranges, some 
TABLE 4. A list of parasitoids that emerged from galls collected from oaks at 5 locations (Slovenian Littoral) with appropriate hosts. Species in bold emerged from oak galls and from D. kuriphilus galls collected at the same location.

\begin{tabular}{|c|c|c|c|c|}
\hline Host on oak & Orehovica & Kromberk & Grgarske Ravne & Renče - Merljaki \\
\hline 1 Andricus quercuscalicis & & & $\begin{array}{l}\text { Cecidostiba } \text { sp. }^{a} \\
\text { Eupelmus urozonus }^{\mathrm{a}}\end{array}$ & \\
\hline 2 A.quercustozae & & Sycophila sp. $^{\mathrm{a}}$ & \multicolumn{2}{|l|}{$\begin{array}{l}\text { Eurytoma brunniventris }{ }^{\mathrm{a}} \\
\text { Torymus } \mathrm{sp} .^{\mathrm{a}} \\
\text { Megastigmus dorsalis }^{\mathrm{a}}\end{array}$} \\
\hline 3 Biorrhiza pallida & 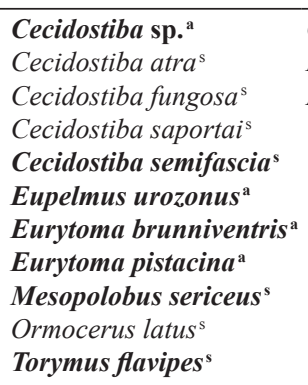 & $\begin{array}{l}\text { Cecidostiba semifascias } \\
\text { Eupelmus annulatus }^{\text {s }} \\
\text { Mesopolobus sericeus }\end{array}$ & & \\
\hline 4 Cynips cornifex & & 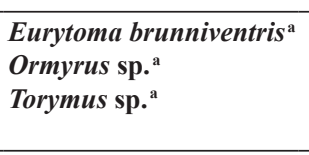 & & $\begin{array}{l}\text { Eupelmus urozonus }{ }^{\mathrm{s}} \\
\text { Ormyrus } \text { sp. }^{\mathrm{a}} \\
\text { Eurytoma } \\
\text { brunniventris }^{\mathrm{a}}\end{array}$ \\
\hline 5 C. quercus & & & $\begin{array}{l}\text { Sycophila sp. }{ }^{a} \\
\text { Torymus sp. }{ }^{a}\end{array}$ & \\
\hline 6 C. quercusfolii & & & $\begin{array}{l}\text { Ormyrus sp. }{ }^{a} \\
\text { Torymus } \text { sp. }^{a}\end{array}$ & \\
\hline 7 Neuroterus albipes & & & Aprostocetus aethiops $^{\mathrm{s}}$ & \\
\hline 8 N. anthracinus & Mesopolobus tibialis $^{s}$ & & & \\
\hline 9 N. lanuginosus & & & Aprostocetus sp. ${ }^{\mathrm{a}}$ & \\
\hline 10 N.numismalis & $\begin{array}{l}\text { Mesopolobus fasciiventris } \\
\text { Mesopolobus sericeus }^{\text {s }}\end{array}$ & & & \\
\hline 11 N. quercusbaccarum & & & Torymus flavipes $^{\mathrm{s}}$ & \\
\hline 12 Trigonaspis synaspis & & & & \\
\hline 13 Buds & Sycophila sp. ${ }^{\mathrm{a}}$ & Megastigmus dorsalis $^{\mathrm{a}}$ & 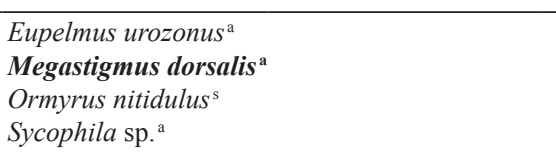 & \\
\hline 14 Catkins & & 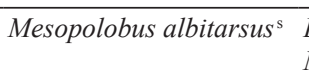 & $\begin{array}{l}\text { Baryscapus pallidae } \\
\text { Mesopolobus mediterraneus }{ }^{\mathrm{s}}\end{array}$ & \\
\hline Unknown host & & & Mesopolobus tibialis $^{\mathrm{s}}$ & \\
\hline
\end{tabular}

${ }^{\text {a }}$ Emerged from asexual oak galls; semerged from sexual oak galls.

of them are also recorded as facultative hyperparasitoids. The most abundant potential hyperparasitoid species was E. urozonus, which was recorded in all years and at almost all locations with ACGW and made up $18 \%$ of all the parasitoids that emerged. Some other ectoparasitoids, such as T. auratus (Geoffroy in Fourcroy) and E. brunniventris Ratzeburg, can also act as facultative hyperparasitoids and are cannibalistic attacking any larva they encounter within a gall (Hayward \& Stone, 2005). The species E. urozonus and E. vesicularis (Retzius) can also attack primary parasitoids of the larvae of a range of Lepidoptera, Diptera and Coleoptera and are thus very polyphagous (Hayward \& Stone, 2005). These species also have the broadest range of cynipid hosts and are able to develop as ectoparasitoids on a great range of other parasitoids. Although we did not record parasitoid species from rose galls, other than $E u$ rytoma rosae Nees (unpubl. data), there are several spe- cies, i.e., E. urozonus, Sycophila biguttata (Swederus), S. flavicollis, M. sericeus and Aulogymnus skianeuros (Ratzeburg), that also attack oak and rose cynipids. However, individual parasitoid species generally attack only galls induced by members of a single cynipid tribe but different tribes are commonly attacked by the same parasitoid genera (Csóka et al., 2005).

\section{CONCLUSIONS}

Our results on the parasitoid fauna of ACGW indicate that the time required for native parasitoid species to adapt to a new abundant host is fairly short, since 9 species of native parasitoids belonging to 5 Chalcidoidea families were recorded in Slovenian Styria and Lower Carniola only one or two years after the first appearance of ACGW galls. The introduced species $T$. sinensis is not yet present throughout Slovenia but was introduced at 6 locations in 2015. There 
are currently 27 species of native parasitoids recorded emerging from ACGW in Slovenia, but based on data from Italy, China, Japan and Korea we can expect to record more species in the next few years.

ACKNOWLEDGEMENTS. Research was supported by The Phytosanitary Administration of Republic Slovenia. We thank J. Ernst (Institute of Evolutionary Biology, Edinburgh University, Edinburgh) for identifying the parasitoids reared from oak gallwasps. G. Melika was supported by a grant from the Hungarian Academy of Sciences (OTKA K101192).

\section{REFERENCES}

Abe Y., Melika G. \& Stone G.N. 2007: The diversity and phylogeography of cynipid gallwasps (Hymenoptera: Cynipidae) of the Oriental and Eastern Palearctic regions, and their associated communities. - Orient. Insects 41: 169-212.

Aebi A., Schönrogge K., Melika G., Alma A., Bosio G., Quacchia A., Picciau L., Abe Y., Moriya S., Yara K., Seljak G. \& Stone G.N. 2006: Parasitoid recruitment to the globally invasive chestnut gall wasp Dryocosmus kuriphilus. In Ozaki K., Yukawa J., Ohgushi T. \& Price P.W. (eds): Ecology and Evolution of Galling Arthropods and their Associates. Springer, Tokyo, pp. 103-121.

Aebi A., Schönrogge K., Melika G., Quacchia A., Alma A. \& Stone G.N. 2007: Native and introduced parasitoids attacking the invasive chestnut gall wasp Dryocosmus kuriphilus. Bull. OEPP/EPPO 37: 166-171.

ARSFSVSPP - Administration of the Republic of Slovenia for Food Safety, Veterinary Sector and Plant Protection. Ministry of Agriculture AND the EnVIronment 2014: Kostanjeva šiškarica - Dryocosmus kuriphilus Yasumatsu. http://www. uvhvvr.gov.si/si/delovna_podrocja/zdravje_rastlin/posebno_ nadzorovani_organizmi/kostanjeva_siskarica/ Accessed 6 February 2014

Askew R.R., Melika G., Pujade-Villar J., Schönrogge K. \& Stone G.N. 2013: Catalogue of parasitoids and inquilines in cynipid oak galls in the West Palaearctic. - Zootaxa 3643: $1-133$.

Bailey R., Schönrogge K., Cook J.M., Melika G., Csóka G., Thuroczy C. \& Stone G.N. 2009: Host niches and defensive extended phenotypes structure parasitoid wasp communities. — PLoS Biology 7(8): doi:10.1371/journal.pbio. 1000179.

Bosio G., Armando M. \& Moriya S. 2013: Verso il controllo biologico del cinipide del castagno. - Informat. Agr. 14: 60-64.

CoOper W.R. \& Rieske L.K. 2007: Community associates of an exotic gallmaker, Dryocosmus kuriphilus (Hymenoptera: Cynipidae), in Eastern North America. - Ann. Entomol. Soc. Am. 100: 236-244.

Csóka G., Stone G.N. \& Melika G. 2005: Chapter 5: Biology, ecology and evolution of gallinducing arthropods. In Raman A., Schaefer C.W. \& Withers T.M. (eds): Biology, Ecology and Evolution of Gall Inducing Cynipidae. Vols 1, 2. Science Publishers, Enfield, NH, pp. 573-642.

Drevo, Gozd, Les 2011: Statistical office of the Republic of Slovenia, Ljubljana. http://www.stat.si/doc/pub/LES-slo-internet. pdf Accessed 7 Febuary 2014.

Francati S., Alma A., Ferracini C., Pollini A. \& Dindo M.L. 2015: Indigenous parasitoids associated with Dryocosmus kuriphilus in a chestnut production area of Emilia Romagna (Italy). - Bull. Insectol. 68: 127-134.

Gibbs M., Schönrogge K., Alma A., Melika G., Quacchia A., Stone G.N. \& AeBi A. 2011: Torymus sinensis: a viable man- agement option for the biological control of Dryocosmus kuriphilus in Europe? - BioControl 56: 527-538.

Graziosi I. \& SANTI F. 2008: Chestnut gall wasp (Dryocosmus kuriphilus): spreading in Italy and new records in Bologna province. - Bull. Insectol. 61: 343-348.

HaYward A. \& Stone G.N. 2005: Oak gall wasp communities: Evolution and ecology. - Basic Appl. Ecol. 6: 435-443.

Jurc M., Mihajlović L., Fernández M.F. \& Borkovič D. 2013: Differences in occurrence of Dryocosmus kuriphilus parasitoids depend on time on chestnut gallwasp introduction to Slovenia and Spain. In Radócz L. (ed.): Proc. of II. European Congress on Chestnut, Debrecen, Hungary, 9-12 October 2013. Book of Abstracts. International Society for Horticultural Science, Debrecen, p. 45.

Knapič V., Seljak G. \& Kolšek M. 2010: Experience with Dryocosmus kuriphilus Yasumatsu eradication measures in Slovenia. - Bull. OEPP/EPPO 40: 169-175.

MatošEvić D. \& Melika G. 2013: Recruitment of native parasitoids to a new invasive host: first results of Dryocosmus kuriphilus parasitoid assemblage in Croatia. - Bull. Insectol. 66: 231-238.

Melika G., Matošević D., Kos K., Bosio G., Kriston É., Krizbai L., Bozsó M. Csóka G., Pénzes Z. \& Quacchia A. 2013: Native parasitoids attacking the chestnut gallwasp, Dryocosmus kuriphilus (Hymenoptera: Cynipidae), across Italy - Slovenia - Croatia - Hungary. In Radócz L. (ed.): Proc. of II. European Congress on Chestnut, Debrecen, Hungary, 9-12 October 2013. Book of Abstracts. International Society for Horticultural Science, Debrecen, p. 46.

Murakami Y., Ao H.B. \& Chang C.H. 1980: Natural enemies of the chestnut gall wasp in Hopei Province, China (Hymenoptera: Chalcidoidea). - Appl. Entomol. Zool. 15: 184-186.

Quacchia A., Moriya S., Bosio G., Scapin I. \& Alma A. 2008: Rearing, release and settlement prospect in Otaly of Torymus sinensis, the biological control agent of the chestnut gall wasp Dryocosmus kuriphilus. - BioControl 53: 829-839.

Quacchia A., Ferracini C., Nicholls J.A., Piazza E., SAladini M.A., Tota F., Melika G. \& Alma A. 2012: Chalcid parasitoid community associated with the invading pest Dryocosmus kuriphilus in north-western Italy. - Insect Conserv. Divers. 6: 114-123.

Quacchia A., Bosio G. \& Moriya S. 2014: Effectiveness of Torymus sinensis in the biological control of Dryocosmus kuriphilus in Italy. - Acta Horticult. 1043: 199-204.

SAnTI F. \& MaInI S. 2011: New association between Dryocosmus kuriphilus and Torymus flavipes in chestnut trees in the Bologna area (Italy): first results. — Bull. Insectol. 64: 275-278.

Schluter D. 2000: The Ecology of Adaptive Radiation. Oxford University Press, Oxford, 296 pp.

Stone G.N., Schönrogge K., Atkinson R.J., Bellido D. \& PuJADE-VILLAR J. 2002: The population biology of oak gall wasps (Hymenoptera: Cynipidae). - Annu. Rev. Entomol. 47: 633668.

Szabó G., Kriston É., Bujdosó B., Bozsó M., Krizbai L. \& Melika G. 2014: The sweetchestnut gallwasp (Dryocosmus kuriphilus Yasumatsu, 1951) (Hymenoptera: Cynipidae): current distribution in Hungary and its natural enemies. - Növényvédelem 50(2): 49-56.

Weiner E. \& Keddy P.E. 1999: Ecological Assembly Rules: Perspectives, Advances, Retreats. Cambridge University Press, Cambridge, $432 \mathrm{pp}$.

Received May 21, 2015; revised and accepted July 24, 2015 Prepublished online August 27, 2015 